\title{
Study on the Application of Innovation Education in Higher Vocational Physical Education under the New Curriculum Reform
}

\author{
Xiaofeng Mou \\ Qingdao Technical College (China Qingdao 266555)
}

Keywords: Higher vocational physical education; Innovative education; Current situation; Methods

\begin{abstract}
In the knowledge economy age, knowledge and technology are rapidly renewed, and only that adapts to the environment can survive. If we want to fight for a place in this society, we must establish the idea of lifelong learning, innovate in education and promote the development of students in a comprehensive, autonomous and individual manner. As an important part of quality education, physical education must naturally undergo innovation and reform. The article explores the situation of physical education teaching in higher vocational colleges and explores the aspects that do not meet the needs of innovative education, and proposes corresponding solutions to promote its innovation and development.
\end{abstract}

With the continuous progress of society, the demand for talents in various industries has greatly increased. At the same time, the requirements for the quality of talents have also increased. This also increases the difficulty of teachers' teaching. Teachers must also cultivate students' practical skills, innovative awareness and ability to learn independently while teaching students theoretical knowledge. In physical education, teachers must combine the current industry status to innovate teaching methods, pave the way for students' future careers, and seize the opportunity of the new curriculum reform to promote the efficient development of innovation education in higher vocational physical teaching.

\section{Part One The Situation of Higher Vocational Physical Education}

\section{Student Sources are Complex and the Quality is Uneven}

As far as the current situation is concerned, there are main two sources of students in higher vocational schools. The students who have lost their positions in the college entrance examination have more or less frustration and sense of loss in their psychological state. The students who have accepted three years of education continued to study in secondary schools are full of expectations for university life. Therefore, due to the complexity and diversification of the structure of student members, there are some obvious disadvantages of higher vocational physical education: firstly, many students come from rural areas and towns, and the received physical education is relatively inadequate. The sports facilities in village and town schools are relatively scarce. Many students find it difficult to participate in sports activities. Therefore, it is difficult for students to develop proper sports awareness and sports concepts. Secondly, The psychological gap brought about by the great contrast makes it difficult for students to truly integrate into sports activities and do not have much enthusiasm for sports activities. In summary, higher vocational physical education teachers are likely to encounter bottlenecks in their teaching.

\section{Teaching Mode of Physical Education in Higher Vocational School is Traditional}

In the teaching of higher vocational schools, "application" is used as the main purpose and characteristics to construct curriculum and teaching content. The goal of "accommodating social needs" is to cultivate the technical talents required by the society, and teaching skills are mainly used in teaching. It is easy to neglect physical education for students. In higher vocational school, the teaching of each specialized course is often combined with the social employment department to strengthen the teaching mode of practical teaching. However, this teaching model is not targeted in physical education teaching. In teaching, higher vocational physical education adheres to the "four-unified" education pattern and advocates the unification of four aspects of teaching materials, outlines, schedules and assessments, but ignores the different requirements for distinguishing 
majors from sports and different students' different interests in physical education. When taking teaching physical education, disregarding students' interests easily makes students feel sick about sports and is not conducive to the development of physical education. If the physical education teaching mode of higher vocational colleges can't realize concrete analysis of specific problems which will only hinder the development of physical education teaching in higher vocational school.

System Defects Limit of Higher Vocational School on Physical Education. Students in higher vocational schools generally have two years of time to study skills in schools, and then they must conduct social practice (at least one year's internship). Under this system, students have limited physical education time in school. If all teaching objectives are to be completed within a limited time, students' learning will only be surface and it will be difficult to learn the essence. In addition, during the students' internship, it is difficult to have time for physical exercise because of the time constraints and work. In addition, because of the emphasis on the teaching of technology in higher vocational education, there are few special teaching links in physical education. Students find it difficult to find their favorite sports, and after graduation, they usually work on the production management, and they have no time to participate in sports activities.

\section{Part Two The Method of Promoting Combination of Creative Education and Higher Vocational Physical Education Teaching}

\section{Insisting on Promoting Innovation in Physical Education Activities}

The physical education activities in higher vocational education must keep pace with the times and maintain its own uniqueness. Physical education should not be confined to existing sports activities, such as running and playing basketball. Teachers can also develop new teaching activities, such as relaying (increase teamwork abilities among students), practicing Tai Chi (Training students' minds, tempering students' willpower), aerobics (testing students' physical coordination ability) and other activities to promote students' all-round development. At the same time, teaching activities should not be confined to schools. We must change the pattern of schools, teachers and playgrounds as the center, and expand as far as possible. For example, we can organize students to ride relay races around the city and organize students to perform hiking activities. This not only increases the interest of physical education, but also easily stimulates students' enthusiasm to achieve the purpose of developing physical education.

Insisting on Teaching Students in Accordance with Their Aptitude and Promoting the Reform of Physical Education Courses in Higher Vocational School

There are many different majors in higher vocational school, and the requirements for sports in each major vary greatly. This requires that teachers should not rely on their abilities to teach. For example, a flight attendant professional student should request a "soft beauty" of the body, and if the teacher teaches a flight attendant professional like a student who teaches a sports major, it is not conducive to the development of a flight attendant professional student. Therefore, teachers should make arrangements in accordance with the students' professionalism, and such physical education activities will also greatly benefit students' professionalism. In the teaching activities, teachers can divide the sports teams according to their professional requirements, physical fitness, sports hobby and so on. Each group conducts their own activities. Micro-sports events can be held at the end of the semester to test student learning outcomes. In the process, teachers must evaluate students' activities and students are motivated to actively participate in activities. Teachers must also guide students in the types of activities to be carried out. Nowadays, higher vocational physical teaching courses are often complicated. Students may use one semester to learn to play football and Tai Chi. This makes it difficult for students to learn. Under the innovative education of the new curriculum reform, teachers can innovate teaching content, avoid sports with higher degree of difficulty, and try to allow students to independently choose a sports activity and adhere to the "learning and perfecting" teaching method, which can really realize the charm of sports and improve students' comprehensive qualities of sports. 


\section{Adhere to the Unity of Humanistic Ideas and Teaching Achievements}

With the importance of education, teachers should strengthen their influence on students' humanities in their teaching activities and make physical education classes a the "real" physical education class. On the one hand, teachers can combine physical education with traditional Chinese culture in teaching. And teachers can explain some of the traditional sports activities that can be associated with modern sports in ancient China, such as football and cricket. This will not only promote our outstanding on traditional culture, but also enhance students' national self-confidence and pride, invigorate the atmosphere, improve the classroom effect, inspire students' passion for sports and allow students to actively participate in sports activities. On the other hand, students in higher vocational schools will inevitably encounter health care, occupational diseases and other problems in their future careers. Teachers can appropriately impart some health knowledge to students so that they can recognize the benefits of physical exercise. Therefore, teachers can open up some exercises to lower body, such as body shape, long-distance running and so on to help students improve their own strength. In addition, the school can start from the needs of various professional schools, summarize the existing educational resources of the school and develop a variety of physical education courses so that students can have more choices.

\section{Adhere to the Unity of Students' Physical and Mental Health}

The core idea of the "new curriculum reform" is "to insist on everything for the development of students" and students are the main body of development. Higher vocational students are at a time of youth, and it is time of forming individuality, but it is also when there is a lot of psychological pressure. Therefore, teachers should also improve students' psychological quality while improving their physical quality. The pressure of the average student mainly comes from schoolwork, friends, family and lovers. This requires the teacher to observe the student's behavior seriously in the teaching. Generally speaking, students who have little enthusiasm for the sports activity have psychological pressure. The teacher should give prompt guidance (which can give him some earnest suggestions) and sincerely talk to him. In the usual teaching, teachers can also organize students to watch positive films to guide students to establish positive thinking. Teachers can also organize some group activities or some more interesting sports games to promote exchanges and understanding among students so that students can live in harmony.

\section{Persisting in Training Students to Set Up a Correct Sense of Physical Education}

Sports consciousness refers to the active psychological activities produced by students in sports activities consciously recognizing the meaning and function of sports activities, which is manifested in the awareness of sports importance and the consciousness of sports activities. A correct sense of sports can improve students' enthusiasm and initiative in participating in sports activities, promote the development of their own quality and enable students to achieve the unity of body beauty and spiritual beauty. Nowadays, students are restricted by the internal factors such as school, family and other factors including their cultural accomplishment and physical quality that results in students' weak sense of sports and weak sense of initiative participation. It is difficult for students to enjoy sports activities. Teachers should pay attention to developing students' sports consciousness in teaching, developing happy sports, publicizing the advantages of sports, creating a strong atmosphere for physical exercise, cultivating students' sense of sports and laying a solid foundation for establishing lifelong sports consciousness.

\section{Conclusion}

Under the new situation, the trend of higher vocational education is already quality education, and the innovation of higher vocational physical education is imperative. Teachers should persist in improving subject quality, updating teaching concepts, innovating teaching models and promoting the innovative development of physical education. Teachers must also promote the overall development of students and improve the overall quality of students. In the trend of the new curriculum reform, higher vocational physical education in the teaching mode of continuous innovation and development in order to better achieve the educational goals for the community to provide all-round development of high-quality talent. 


\section{Reference}

[1] Yuhao Wang. Study on the application of innovation education under the new course in higher vocational physical education[J].Knowledge Economy,2017(24):147+149.

[2] Shan Zhang. The application of the new curriculum to the innovation education in the higher vocational physical education[J].Wisdom,2017(21):2. 